\title{
Dementia as a contemporary challenge for providing care for the aging populations
}

\author{
Alicja Klich-Rączka (i) https://orcid.org/0000-0002-9311-0078
}

Department of Internal Medicine and Gerontology, Jagiellonian University Medical College, Kraków

Address for correspondence: Katedra Chorób Wewnętrznych i Gerontologii, Śniadeckich 10, 31-531 Kraków, ala_klich@o2.pl

\section{Abstract}

Dementia occurs with a frequency of $10-12 \%$ in the entire geriatric population and $33-50 \%$ in people over 90 years of age. The most common cause of dementia are: Alzheimer's disease, rarely vascular dementia, dementia with Lewy bodies, frontotemporal dementia and Parkinson's disease with dementia. There are no medicaments to prevent dementia and effectively treat it. The treatment only slows the progression and improves the quality of life of the patient and caregiver. Taking care of a patient with dementia burdens the caregiver. As the disease progresses, care time extends even to the entire day. Over $90 \%$ of caregivers in Poland are family carers. Over $90 \%$ of patients stay in their own home until death. The cost of care is high and increases with the duration of the disease. In the case of agitated patients, the cost is higher. Institutional care is more expensive than home care. In Poland, there are no good system solutions in care for a dementia patient. Caregivers do not receive proper support from the government and subordinate units.

\section{Key words: Alzheimer's disease, hehavioral disorders, dementia, care, care costs}

Stowa kluczowe: choroba Alzheimera, koszty opieki, opieka, otępienie, zaburzenia zachowania

Ministerstwo Nauki i Szkolnictwa Wyższego
Przygotowanie do wydania elektronicznego finansowane w ramach umowy 637/P-DUN/2019 ze środków Ministerstwa Nauki i Szkolnictwa Wyższego przeznaczonych na działalność upowszechniającą naukę.

\section{Introduction}

According to the definition of the World Health Organization, society is considered to be demographically old if the percentage of people aged $\geq 65$ years exceeds $7 \%$. Poland reached this age threshold in the second half of the twentieth century, and the aging of the population has now become a very significant and growing problem. In 1990 the percentage of population aged 65 or above in our country was $10.1 \%$, in 2000 it increased to $12.3 \%$, in 2010 to $13.4 \%$, in 2016 to $16.1 \%$, and in 2017 to $16.7 \%$ [1]. The reason for this is not only the constant extension of human life, but also the decreasing number of births, which in effect means a steadily decreasing percentage of people of pre-working age compared to people of retirement age. Already in 1998 in Poland the number of births was lower than the number of deaths [1]. As a consequence, the number of people meeting the health and care needs of a growing group of people potentially requiring care is diminishing. The so-called demographic dependency ratio used to assess these needs (the percentage of people aged $\geq 65$ in relation to people aged 15-64) has been growing significantly over the last few years. Therefore, according to forecasts, the index conventionally adopted in Poland would amount to the value of 100 in 2000, to 102 in 2010 , to about 148 in 2020, 189 in 2030, 2012 in 2040, and 281 in 2050 [2]. This poses a growing challenge for the health care system and for the social policy of the state to secure the health and care needs increasing with age. Ageing is inextricably linked with the growing problem of multiple morbidities, polypharmacy and incapacity.

According to the PolSenior study, representative of the Polish geriatric population, conducted in $2007-2011,62 \%$ of people aged $\geq 65$ years reported multiple morbidities, defined as the existence of at 
least 2 diseases (mean age of the studied group was 79.4 years) - of the group, $43 \%$ had at least 3 diseases and $29 \%$ had 4 or more diseases [3]. The most common diseases in the study population were of cardiovascular type: hypertension in $61 \%$, arrhythmia in $36 \%$ and ischaemic heart disease in $22 \%$. Diabetes was reported in $19 \%$ of the population, respiratory diseases in $18 \%$, osteoporosis in $18 \%$, thyroid diseases in $12 \%$, heart failure in $11 \%$. Of the people analyzed in the PolSenior study (taking into account patient history), more than $10 \%$ reported the occurrence of mental diseases, including dementia and depression. However, screening diagnostics of dementia and depression carried out in the cited project showed a much more frequent prevalence of these diseases in old age. Cognitive dementia was found in $12.1 \%$, mild cognitive disorders, not yet fulfilling the criteria of dementia, were found in another $36 \%$. Depression of various severity was observed in about $30 \%$ of the studied population [4].

In addition, the PolSenior study revealed a huge prevalence of sensory disabilities: visual disturbances were observed in $40 \%$ of elderly people, hearing disorders in $32 \%$, balance disorders and falls in $30 \%$. In a year, a fall occurred in every 3 persons over 65 years of age, in every second person over 80 years of age, with such complications as: injuries, fractures, increased risk of incapacity and institutionalisation (the consequences of falls constitute $40 \%$ of the causes of admissions to nursing homes), loss of independence, reduced quality of life, increased prevalence and mortality [5].

With age, there is also a significant deterioration of motor and self-service abilities. According to a study by PolSenior of people aged $65-69$, about $77 \%$ of men and $88 \%$ of women are still independent in everyday life, which means that they do not need any help in performing such activities as: making a phone call, preparing a simple meal, doing basic shopping, taking medicines, disposing of their own money. However, in advanced old age, after the age of 90 , only $14 \%$ of men and $7 \%$ of women are independent in these activities. At the threshold of old age, women are fitter and they also live longer than men (currently in Poland the average age for women is 82 years, for men - 74) [1]. Late old age is less common for men, but in this period of life they are more able than women. The reason for such a clear deterioration of functional efficiency with age is primarily the growing cognitive disorders, as well as the deterioration of sensory and locomotor organs, and the previously discussed multiple morbidities [5].

In the light of the above mentioned coexisting diseases and disabilities, the care of a patient with cognitive dementia is a very difficult and complex issue, especially in late old age. Dementia, due to the nature of the disease, is one of the most important large geriatric syndromes, constituting one of the most frequent and most difficult health problems in the elderly population. It significantly deteriorates the quality of life of patients, generates immense costs of therapy and care, and in the advanced period of disease is the main reason for institutionalization.

\section{Diagnosis of dementia}

According to the most commonly used WHO definition in the world (ICD-10, 1992), dementia is a syndrome caused by a brain disease, usually of a chronic or progressive nature, where higher cortical functions (cognitive functions) are disturbed, such as memory, thinking, orientation, understanding, counting, learning ability, language and assessment. According to this definition, cognitive impairment is usually accompanied, or sometimes preceded, by disturbances in the emotional-motivational sphere and decrease in control over behavior. They are often a bigger problem in therapy and care than the axial symptoms of dementia, which are cognitive disorders [6].

Dementia is most often caused by neurodegenerative changes, including Alzheimer's dissease (AD), which accounts for $35-70 \%$ of all dementia cases $[7,8]$. The slightly rarer neurodegenerative disorders include dementia with Lewy bodies (DLB, 20-25\%), frontotemporal dementia (FTD, 10-15\%) and Parkinson's disease with dementia (PDD, approx. 5\%).

Vascular dementia (VaD) is a less common cause of dementia than neurodegenerative diseases. The Vascular Dementia (VaD) disorders account for $30 \%$ of all cases of this syndrome. However, pure vascular dementia is rare (about $5 \%$ of all dementias) and most often coexists with AD.

Occasionally dementia may be caused by other diseases, including: progressive supranuclear palsy, corticobasal degeneration, Creutzfeldt-Jakob disease, Hakim-Adams syndrome, Huntington's disease, hereditary congophilic angiopathy, dementia in the course of Down's syndrome [6].

Cognitive dysfunctions in geriatric patients may also be caused by factors causing the so-called pseudodementia, also referred to as potentially reversible dementia. The group of such causes includes: diseases of the central nervous system (both primary and metastatic brain tumors, chronic subdural hematoma and other consequences of craniocerebral injuries, neuroinfections), deficiency syndromes (mainly vitamin $\mathrm{B}_{12}$ deficiency), somatic diseases (hypothyroidism, poorly controlled diabetes, especially with chronic hypoglycaemia, organ failure, especially of the heart, respiratory system, liver or kidneys, water-electrolyte metabolism disorders, especially hyponatremia and hypernatraemia, inflammatory and neoplastic diseases). Cognitive dysfunctions may also be caused by abnormalities in the pharmacotherapy of elderly people (they may occur especially when using neuroleptics, sedatives and sleeping pills, as well as analgesics). The diagnosis of cognitive disorders in some cases should also take into account the alcoholic background and its occurrence in mental diseases (especially in depression and schizophrenia) [6].

\section{Prevalence of dementia}

The prevalence of dementia in the entire geriatric population is, according to various studies, about $10-12 \%$, 
with a marked increase in the prevalence of this disease in subsequent age groups. At the threshold of old age, dementia is observed in just a few percent of people, but after 80 years of age - in about $20 \%$, and $\geq 90$ years of age - in as many as 33-50\% of people [9]. In the PolSenior study, dementia-related cognitive dysfunction increased from $9.5 \%$ in the $65-69$ age group, to $10.1 \%$ in the $70-74$ age group, $14.5 \%$ in the $75-79$ age group, $15.6 \%$ in the $80-84$ age group, and $20.9 \%$ in the 85-89 age group. In the oldest group (aged 90 and above) cognitive dementia-indicating disorders were found in $34.4 \%$ of respondents [10].

The enormous prevalence of dementia in the elderly population is a very important problem from the point of view of geriatric care in the broad sense of the term. This also results in enormous costs associated with the provision of appropriate care both in the patient's place of residence and in the form of institutional care.

\section{Pathogenesis of dementia}

The main pathogenetic factor in Alzheimer's disease is the presence of pathological proteins, among them $\beta$-amyloid $(\mathrm{A} \beta)$ and hyperphosphorylated tau protein, which lead to neuronal loss, deterioration of their function and damage to synaptic connections, mainly in the hippocampal area. $\beta$-amyloid is characterized by aggregation and extracellular deposition between neurons in the form of amyloid plaques. On the other hand, tau protein accumulates inside neuronal cells, causing neurofibrillary degeneration. Both pathological proteins lead to damage and death of neurons, which results in a decrease in the production of brain messengers, mainly acetylcholine. The level of other neurotransmitters such as noradrenaline, serotonin and dopamine is also reduced in this type of dementia.

Except for sporadic cases of familial forms of $\mathrm{AD}$, the current state of knowledge finds no genetic background for these disorders. More than $95 \%$ of cases of dementia in the course of Alzheimer's disease have no hereditary etiology. In view of the above, genetic testing is not currently recognized as a useful and recommended tool in routine diagnosis of the disease. Age is the only indisputable risk factor for Alzheimer's disease. Other discussed predisposing factors for AD include: lack of education, low physical activity, poor family and social contacts. In recent years, the significant role of vascular factors in the risk of developing $\mathrm{AD}$ has also been increasingly emphasized.

Dementia with Lewy bodies is caused by the presence of Lewy bodies in the neo-cortex and limbic cortex bodies containing deposits of $\alpha$-synuclein protein. The cause of these changes is unknown, and the genetic background of the disease has not been proven.

In frontotemporal dementia, deposition occurs in the area of the frontal and/or temporal lobes in neurons or glial cells of inclusion bodies consisting of hyperphosphorylated tau protein or ubiquitin. Approximately $30-50 \%$ of FTD cases have a family history of the condition.
Vascular dementia has a multifactorial, complex ischemic or hemorrhagic etiology. It occurs in the course of various cerebral vascular diseases (massive and minor strokes as a complication of large vessel disease, complications of small vessel disease, intracerebral hemorrhage, vasculitis, angiopathy) $[6,8,9]$.

\section{Diagnosis and recognition}

According to current knowledge, a 100\% pre-mortem diagnosis of dementia in the course of Alzheimer's disease is not possible; this diagnosis is only likely. Unambiguous confirmation of the diagnosis is possible only after histopathological examination of the brain tissue. In the screening diagnosis of cognitive impairment, the Mini Mental Test Examination (MMSE), Clock Drawing Test (CDT) and the Montreal Cognitive Assessment (MoCA) are most commonly used. The MoCA test is especially recommended for the diagnosis of early stage dementia and mild cognitive impairment (MCI) usually preceding the clinical stage of Alzheimer's disease or other types of dementia. In psychological diagnostics of cognitive disorders, the following are most often recommended: Trail Making Test, California Verbal Learning Test, Verbal Fluency Test, Rey Complex Figure Test, and ADAS-Cog (Alzheimer's Disease Assesment Scale - Cognitive Subscale). According to current criteria, in the diagnosis of dementia there is also a need to conduct a neuroimaging examination, primarily to exclude other causes of cognitive impairment. The Polish Alzheimer's Society (Pol. PTA) recommends nuclear magnetic resonance imaging (MRI) as the main diagnostic tool in clinical practice. PET and SPECT tests are only recommended for differential diagnosis in doubtful cases. In situations where it is not possible to perform an MRI examination, computed tomography is used.

Determination of biomarkers in the cerebrospinal fluid (in which there is a decrease in the level of $A \beta 42$ peptide, an increase in hyperphosphorylated tau protein) also plays a supporting role in the diagnosis of dementia. However, the use of biomarker tests for routine clinical practice is not recommended, and a diagnosis of dementia in AD cannot be made solely based on the results of biomarker tests in cerebrospinal fluid or neuroimaging [6].

Currently, in the diagnosis of dementia in AD most commonly used are the criteria based on 1994 DSM-IV, 1992 ICD-10 (WHO) and 2011 NIA/AA (National Institute on Aging/Alzheimer's Disease Association) [6]. According to the NIA/AA criteria, three stages of Alzheimer's disease are distinguished. The first two of them (asymptomatic - preclinical and mild cognitive impairment) precede the onset of clinical symptoms of dementia for many years. According to these clinical criteria, the basis for the diagnosis of mild cognitive impairment are the following symptoms: concern related to a change in cognitive performance reported by the patient, informant or clinician, objective evidence of deterioration in one or more cognitive areas, but the independent ability to function daily is maintained and there are no 
symptoms of dementia. According to the current state of knowledge, MCI is not an indication for the inclusion of pharmacotherapy, although in the vast majority of cases the conversion of MCI to dementia occurs over time. Studies have shown that in people $\geq 65$ years of age, about $15 \%$ of mild cognitive impairment develop into dementia in 2 years, and in 10 years of observation - over $90 \%[11,12]$. However, the results of previous studies have not proven the long-term effectiveness of any pharmacotherapy in the prevention of dementia, and the risk of side effects and the cost of therapy far outweigh the possible benefits $[11,12]$.

In the diagnosis of dementia with Lewy bodies, the 2005 criteria according to McKeith et al. are most often used, among which the most important are: fluctuation of disorders, systematic visual hallucinations, attention deficit disorder and Parkinson's symptoms [6].

Frontotemporal dementia occurs in three basic types: the frontal variant, semantic dementia and progressive aphasia without speech fluency. The diagnosis of this type of dementia is based on several different criteria that enable the diagnosis of particular types of pathologies belonging to this group of disorders (1994 criteria according to Lund and Manchester Group, 1998 criteria according to Neary et al., and 2001 criteria according to McKhanna et al.) [6].

Vascular dementia is a complex, multifactorial etiology, which in consequence determines a very diverse clinical picture, depending on the size, number and location of lesions. There are also many different divisions and diagnostic criteria for this type of dementia. According to PTA, the most commonly used criteria are NINDS-AIREN (National Institute for Neurological Disorders and Stroke with the Association Internationale pour la Recherche et l'Enseignement en Neurosciences, 1993) [6].

In the diagnosis of dementia in Parkinson's disease the 2007 criteria according to Emre et al. are currently in force [6]. The diagnosis of this type of dementia must also meet the so-called one-year condition, which means that clinical symptoms of cognitive disorders occur at least one year after the onset of motor disorders. If these symptoms occur earlier, then LBD should be suspected.

\section{Symptoms of dementia}

The course of dementia in Alzheimer's disease is most often divided into three stages: light (mild), medium (moderate) and significant (deep). In the first stage of the disease, the patient is still relatively independent in self-service, although there may already be slight difficulties in the disposal of money, shopping, using credit cards and performing other more complex activities related to everyday functioning. During this period of illness, it is typical to forget about recent events, difficulties in finding words, descriptive names of objects, frequent repetition of the same questions, partial disorder in time and space orientation. There are no clear difficulties in understanding speech, personality changes or movement disorders.
The second stage of dementia in the course of Alzheimer's disease is characterized by more severe disturbances of fresh and distant memory, and greater difficulty in finding words. There are already initial difficulties in understanding speech, dressing up and maintaining personal hygiene. Difficulties in managing money are more severe than in the first period of illness, and there is also an inability to make complex decisions. The first Parkinson movement symptoms may also appear. During this period of dementia, behavioral disorders are most often accompanied by these symptoms. These symptoms can sometimes appear in the first period of the disease, or occur only in the third stage of dementia. They are recognized by the International Psychogeriatric Association as an integral part of dementia and referred to as behavioral and psychological symtomps of dementia (BPSD).

According to the new nomenclature and new guidelines updated in 2018 for the management of behavioral disorders in dementia, these changes are now also referred to as neuropsychiatric symptoms (NPS) [13].

The authors of these guidelines divided NPS into three groups: behavioral, affective and psychotic disorders. The most common behavioral disorders in dementia include: agitation, anxiety, purposeless walking, verbal and/or physical aggression, shouting, swearing, hostility, constantly asking the same questions, stubbornness, negativity, defiance, apathy, passivity, social withdrawal, clingy attitude towards the caregiver, disinhibition, including sexual disinhibition, shortening the distance in interpersonal relationships leading to inappropriate social behavior. Of affective disorders most common in dementia are emotional lability, depression, anxiety, worrying, phobias, sleep-wake disturbances, sometimes cheerfulness or euphoria, dysphoric reactions and sometimes catastrophic reactions. Among the various psychotic symptoms in dementia, delusions (which may often be paranoid as a result of cognitive disorders, e.g. robbery delusions), hallucinations, as well as misidentification syndromes are most commonly observed.

Of all the listed behavioral disorders in the moderate period of dementia in Alzheimer's disease, apathy, anxiety, irritability, and depression are the most common. In the severe form of dementia observed are the growing scarcity of vocabulary, uttering simple, often illogical sentences, then only single words, often distorted, or newly formed, then single syllables, and ultimately aphonia. There is a lack of speech understanding, no personal hygiene, and loss of sphincter control. As the disease progresses, BPSD symptoms usually increase, especially agitation, anxiety, aggression, and psychotic symptoms. The advanced period of Alzheimer's disease may be associated with Parkinsonian movement disorders, gait and balance disorders, seizures and involuntary movements.

In dementia with Lewy bodies, memory disturbances may not appear in the early stages of the disease, but from the beginning psychotic symptoms, apathy, irritability, repeated, systematized and long-lasting visual hallucinations are present. A characteristic of this type of dementia is the fluctuation of symptoms, imbalance with 
recurrent falls, extrapyramidal symptoms (occurring in approximately $70 \%$ of patients) and a high sensitivity to neuroleptics.

FTD in the frontal form begins with a progressive personality change, behavioral disorder, lack of empathy, criticism and inhibition (including sexual), more severe than in other types of dementia. In the temporal variant (also referred to as semantic dementia) from the beginning of the disease there are deep acquired (semantic) memory disorders with a clear loss of verbal memory, speech is fluent, but loquacious (with the socalled empty speech). In the third variety of the disease (progressive aphasia without fluency of speech), patients have difficulty building sentences, writing and reading from the beginning, while their understanding of speech is relatively good.

Amongst the various forms of vascular dementia, most commonly distinguished are the subcortical dementia, which is caused by multiple lacunar infarcts and white matter damage, and multi-infarct dementia caused by multiple cerebral infarctions, mainly located in the cerebral cortex. Subcortical dementia is characterized by a loss of planning ability, visual-spatial orientation, and executive functions. Memory disorders are less severe, among the symptoms of NPS are mainly depression, emotional lability and personality disorders. These symptoms are accompanied by features of pyramidal and extrapyramidal syndromes, pseudobulbar palsy and sphincter incontinence (in $\mathrm{VaD}$, the lack of sphincter control may occur earlier than in other types of dementia). Focal neurological symptoms coexist in multiinfarct dementia with cognitive impairment. In VaD, the symptoms are quite diverse depending on the location of the lesions. In the presence of changes in the frontal and/or temporal lobes, the symptoms of the disease are similar to the FTD picture. In turn, aphasia, agnosia and apraxia often occur with damage to the parietal lobes, which may resemble the picture of Alzheimer's disease. However, in contrast to AD, vascular dementia is most often characterized by an abrupt course (AD is gradual), with a significantly worse prognosis. Observations of patients show about twice as short survival time of patients with $\mathrm{VaD}$ as compared to patients with $\mathrm{AD}$, and their institutionalization is twice as frequent.

In the course of Parkinson's disease, dementia is observed in about $20-40 \%$ of people diagnosed with this disease. Conducive to the development of this type of dementia are: older age of the patient, longer duration of the disease, course of the disease with greater stiffness and severe motor disorders. In the clinical picture of PDD prevail the features of subcortical dementia, with attention deficit disorder, impaired executive, visual-spatial functions, slowing of thought processes (bradyphrenia), verbal fluency disorder, and lack of initiative. These symptoms are often accompanied by depression, sleep disturbances, apathy, agitation with aggression, anxiety and hallucinations, and delusions. Symptoms of this type of dementia may resemble dementia with Lewy bodies, but movement disorders occur earlier here and precede the features of dementia by at least a year, while in LBD the symptoms of dementia and hallucinations appear in parallel with movement disorders.

Regardless of the etiology, every case of dementia always has an unfavorable prognosis and a similar clinical picture is observed in all types of dementia. In the terminal period of the disease, which determines the final part of major dementia, the patient already becomes completely dependent on the care of other people, does not signal any of his physiological needs. As a result, progressive weakness and disability lead to being bedridden and related medical problems, including thromboembolic complications, pressure sores, muscular atrophy, contractures, malnutrition, infections, especially pneumonia and urinary tract infections. These complications are usually the direct cause of the patient's death. Deterioration of mobility and functional dementia can occur gradually or rapidly, most often after falls, especially when there is a complication in the form of fracture of the proximal femur. The treatment of choice should then be surgery, but due to many contraindications, especially in the presence of other somatic diseases, the procedure is often abandoned, which in the case of geriatric patients, in practice means almost $100 \%$ mortality within a year.

\section{Dementia prevention}

The risk of developing dementia is primarily influenced by non-modifiable factors (mainly age, to a lesser extent, genetic conditions), but also by modifiable factors, and preventive measures are currently focused on them. Based on the results of available research, recommendations on diet and lifestyle in the prevention of dementia have been developed by experts. The most important of these recommendations include: reducing the consumption of animal fats, increasing the consumption of vegetables, fruits, whole grains, fish containing polyunsaturated fatty acids, as well as avoiding vitamin preparations containing iron and copper. Regular physical activity and reduction of cardiovascular risk factors, which increase not only the risk of vascular dementia but also Alzheimer's disease, is also recommended for prophylaxis. It is also recommended to intensify mental activity, which increases cognitive reserve. According to recent studies, the inclusion of these non-pharmacological prophylactic methods, mainly by reducing the most important seven modifiable risk factors for Alzheimer's disease (physical inactivity, hypertension, depression, nicotinism, obesity, diabetes, low education) has reduced the trend to increase the incidence of cognitive impairment with aging population and can potentially reduce the number of AD patients by up to $28.3 \%$ [14].

\section{Non-pharmacological treatment in dementia}

In the treatment of dementia also non-pharmacological methods and pharmacotherapy are used. Non-pharmacological methods include: validation (stimulation of correct social behavior, reduction of anxiety), cognitive therapy (training of memory, orientation in time and space), reminiscing, occupational, environmental 
and music therapies. These methods alleviate mainly behavioral disorders in dementia, improve the quality of life of patients, facilitate falling asleep, and reduce the need for neuroleptics, but have less impact on the intensity of cognitive disorders. In diagnosed dementia, the importance of lifestyle modification and diet recommended to prevent dementia has not been proven to prevent disease progression. The detection and treatment of malnutrition, which is an independent risk factor for death in dementia patients, is of great importance. According to the recommendations of the European Society for Clinical Nutrition and Metabolism (ESPEN), treatment of malnutrition must be an integral part of dementia therapy, which does not inhibit the progression of cognitive disorders, but improves prognosis and quality of life of patients. In the case of eating disorders in patients with mild to moderate dementia, at the time of acute disease increasing protein and energy demand (e.g. infections, perioperative period) it is possible to temporarily apply feeding through a probe or percutaneous endoscopic gastrostomy. In the advanced stage of dementia, especially in its terminal phase, despite the presence of nutritional traits, the difficulties in swallowing, parenteral nutrition, intragastric or percutaneous endoscopic gastrostomy does not improve prognosis, and the use of these invasive methods increases patients' anxiety and deteriorates their quality of life, and according to ESPEN guidelines, the above mentioned methods of therapy are no longer recommended. However, these guidelines recommend hyadration of patients in the terminal dementia period, oral feeding with the use of all possible methods supplementing the food supply (use of oral rich protein and vitamin preparations, liquid thickeners, especially at the risk of choking) [15].

\section{Pharmacotherapy in dementia}

So far, no drugs have been invented that can effectively treat any type of dementia. The recommended pro-cognitive drugs only slow down the progression of the disease and, what is important, improve both the quality of life of patients and their caregivers. Currently, only 3 drugs are registered in Poland to treat dementia. Two of them (donepezil and rivastigmine) belong to the group of acetylcholinesterase inhibitors (AChEI), inhibiting the enzyme that is responsible for excessive degradation of acetylcholine in the brain. The third drug, memantine, is an NMDA receptor antagonist (N-methyl-D-aspartic acid). It has a neuroprotective effect against the toxic effects of glutamic acid and against the accumulation of $\beta$-amyloid deposits and the formation of tau protein.

Donepezil and rivastigmine are recommended for mild to moderate dementia, while memantine is recommended for moderate to severe dementia. According to the guidelines of the Polish Alheimer's Society and other scientific societies dealing with dementia, the use of any other drugs is not recommended.

AChEI drugs are recommended as the main drugs, whereas monotherapy with memantine is recommended especially for contraindications to inhibitors, lack of their effectiveness or poor tolerance. The use of combined therapy with memantine is recommended in the absence of any significant improvement after AChEI.

Before the use of AChEI drugs, especially in older patients with concomitant multiple diseases, the presence of possible contraindications to their use and the risk of side effects versus the benefits of therapy should be carefully considered. The main contraindications for the use of AChEI drugs are: arrhythmias with bradycardia, sinus node disease, active peptic ulcer disease and bronchial asthma. AChEI, through its cholinomimetic effect, may be burdened with a significant risk of bradycardia and life-threatening arrhythmias. The results of many studies indicate a significant increased risk of fainting, falls and doubling the risk of hospitalization in patients receiving donepezil or rivastigmine [16]. The administration of these drugs should be started very carefully and in initial low doses to maximally reduce the risk of adverse effects (bradycardia, nausea, diarrhoea, constipation, vomiting, anxiety, difficulty in urination, fluctuations in blood pressure). The results obtained in recent years also draw attention to the fact that AChEI therapy increases the risk of malnutrition in old age, especially in more advanced stages of the disease. This is another important indication to consider the advisability of therapy in older patients, often malnourished, in whom the risk of side effects from the gastrointestinal tract may reach up to several percent $[17,18]$. Currently, studies are being conducted on the benefits of discontinuation versus continuation of the therapy with these drugs in advanced dementia [19].

If the decision is made to treat dementia with memantine in older patients, the renal function during the therapy should be monitored due to the excretion of the drug in urine in a non-metabolized form. At $40-60 \mathrm{ml} / \mathrm{min}$ GFR, the dose should be reduced to half of its original value, and in the case of more advanced renal failure, the dose should be discontinued. It should be remembered that in older patients, the glomerular filtration capacity decreases physiologically, which at the very start of therapy may be an indication for drug dose reduction.

Studies on new forms of dementia pharmacotherapy (mainly monoclonal antibodies, which preferentially show the ability to bind to $\beta$-amyloid and as a result of dissolution of $\beta$-amyloid deposits and inhibitors of $\gamma$-secretase, which participates in the pathway of $\beta$-amyloid formation from protein precursor) have so far not demonstrated the efficacy of these drugs, which would exceed the risk of their adverse effects. Also cerebrolysin, which is a mixture of peptides, recommended as a potential neurotrophic factor stimulator for several years, has not yet been explicitly registered in the treatment of dementia, despite the fact that there are increasing scientific reports on its effectiveness and safety [20].

\section{Treatment of hehavioral disorders in dementia}

Another difficult problem is the treatment of behavioral disorders and psychotic symptoms in dementia. As 
the results of most studies show, these disorders occur in $80-100 \%$ of patients. The recommended form of NPS therapy, apart from elimination of possible factors stimulating their occurrence (pain, dyspnea, environmental, social and psychological factors), is early inclusion of AChEI and/or memantine into treatment. The recommendations clearly emphasize that classical antipsychotics (including haloperidol and pernazine) cannot be an alternative to second-generation neuroleptics, due to a much higher risk of side effects and even deaths. The results of many meta-analyses show that even new neuroleptics are not devoid of the risk of cardiac arrhythmias, falls, weakness, drowsiness, orthostatic hypotension, metabolic disorders, strokes and increased risk of mortality. For these reasons, it is recommended to use only small atypical neuroleptic doses (quetiapine, tiapridal, olanzapine, risperidone) administered for the shortest possible period of time, if necessary. According to the latest Polish recommendations included in the updated rules of therapy in neuropsychiatric disorders in dementia, the best safety profile among antipsychotics is quetiapine and tiapridal. If new neuroleptics prove ineffective, low doses of carbamazepine or valproate derivatives may be considered in agitation. In sleep disorders in dementia, the so-called sundown syndrome, and in moderate anger and aggression, trazodone is recommended as the first-line drug. However, benzodiazepine drugs should be avoided in older patients because of the high risk of side effects (excessive sedation, walk and balance disturbances, falls, addiction and even increased risk of mortality). In older patients, due to poorer metabolism and elimination of these drugs from the system, the risk of interaction and side effects of benzodiazepine are much higher than in younger patients [13].

\section{Dementia patient care}

As the disease progresses, the patient with dementia becomes increasingly dependent as far as self-service is concerned and increasingly reliant on the caregiver, initially mainly for complex everyday activities, then also for the satisfaction of basic life needs. Initially, the patient requires only periodic control, supervision, support and assistance in the implementation of more complex measures concerning his or her everyday life. Therefore, it can be only occasional help, often several times a week. However, studies from recent years have shown that even in this early stage of the disease, the quality of care for demented patients may not be sufficient. Often, the caregiver does not notice growing cognitive disorders, and the patients themselves, due to better distant memory, appear to have less severe disorders. In a study including a 7-thousand Baltimore geriatric population in its own environment, it was shown that among people with probable dementia, but not yet diagnosed, compared to people who have already been diagnosed with the disease, the greatest problem is that of selfnegligence - the engaging of a patient with cognitive disorders in potentially dangerous actions, if they were inappropriately implemented. These activities included financial management, driving vehicles, preparing hot meals, proper use of medicines, control visits at the clinic [21]. The fact of how often this problem remains unnoticed and the symptoms of dementia are mistakenly attributed to the aging process itself and considered to be a kind of age norm, is confirmed by the fact that despite the improvement in the diagnosis and treatment of dementia, only about $15-20 \%$ of these patients have their problem properly diagnosed and undergo appropriate therapy [22].

As dementia progresses, patient care takes more and more time and changes from helping with everyday activities at the beginning of the disease, to permanent care and nursing activities at a later stage of the disease. According to PTA data, the duration of care increases from about 2.4 hours in the first year of disease duration, to 9 hours in the 5 th year of disease, to the entire day after 10 years of dementia. According to the data of the National Agreement of Alzheimer's Organisations published in 2015, about $90 \%$ of caregivers are family caregivers (including adult children $-62 \%$ and spouses $-32 \%$ ). In $70 \%$ of cases, the carer of the demented patient is a woman. A significant proportion of caregivers are over 70 years of age and face their own medical and functional problems at the same time [22]. Younger caregivers, on the other hand, are often forced to resign from their professional work in order to care for demented patients. Studies of the Polish population show that the family is still the 'main care institution' for dementia patients [23]. However, this care is extremely burdensome and exhausting for the caregiver, and the burden is even greater than for caregivers dealing with cancer patients. Caregivers significantly more often suffer from cardiovascular diseases, depression, degenerative spine, or insomnia [24]. At the same time, this burdening care creates a risk of errors and negligence in the care of demented patients, which, according to recent studies, can be observed even in one in five patients [25].

The burden on the informal carer depends not only on the severity of the disease and symptoms, but also on the support provided by different systemic solutions in a given country. A comparative analysis of this problem conducted in 8 European countries (Estonia, Finland, France, Germany, the Netherlands, Spain, Sweden, the United Kingdom) showed that the burden on caregivers was highest in Estonia and lowest in the Netherlands [26].

\section{Costs of care in dementia}

Dementia is a huge economic burden and the cost of care increases with the severity of the disease. An analysis of these costs in developed countries shows that the costs of care and treatment of dementia are among the highest in the world, after cancer, cardiovascular diseases and stroke [27]. There are no data on the cost of care for dementia patients in Poland.

According to the latest research meta-analyses, the average total annual cost of dementia care in Europe amounts 
to $32,506.73 €$, compared to $42,898.65 €$ in the United States [28]. As the population ages and the risk of dementia increases, these costs are expected to be increasingly borne by society. These figures do not include informal care and other indirect costs, including gratuitous care provided by family carers [29]. The GERAS study comparing expenditure on dementia care conducted in three countries with similar economic status (UK, Germany and France) showed that it differed significantly from one country to another and grew significantly in the subsequent three stages of dementia. Total monthly care costs of mild dementia in France were 1,418, in moderate dementia $-1,737 €$ and $2,453 €$ in significant dementia. In Germany, this expenditure was respectively $1,312 €, 2,412 €$ and $3,722 €$, while in the UK it was $1,621 €, 1,836 €$ and $2,784 €$. [30, 31]. In Spain, the GERAS II study showed that care for patients with mild dementia is $1,514 €$ per month, for patients with moderate dementia 2,082 € per month, and increases to $2,818 €$ in the third stage of the disease. In the same project, in the Italian population, monthly costs in the first stage of the disease were estimated at $1,850 €$, in the second stage, which was interestingly reduced to $1,552 €$, and in the third stage increased again to $2,728 €$. This surprising reduction in the cost of care in the moderate stage of the disease is explained by the effectiveness of the memantine included in the treatment at this stage of the disease [33].

The research also clearly emphasizes that institutional care for dementia patients is much more expensive than home care $[34,35]$. Therefore, in order to delay institutional care, many countries support family carers and invest in community care services [36, 37]. It has also been shown that not only does the duration of the disease generate higher care costs, but also behavioral disorders in dementia, especially agitation. In the case of the predominant symptom, the cost of care may even double [38-40].

\section{Dementia patient care in Poland}

According to estimates from the PolSenior study and the report of the Polish Alheimer's Society, there are about 500-600 thousand people with dementia in Poland, including about 300 thousand with Alzheimer's disease $[4,22]$. However, there is no complete register of dementia patients in our country, which exists in other EU countries, such as the Swedish computer registration system SveDem or the ReDeGi register kept in part of Spain [7]. There are also no data on the cost of care for dementia patients in our country.

In Poland, dementia care is provided by two separate structures under the Ministry of Health and the Ministry of Family, Labour and Social Policy (Pol. MRPiPS). The MRPiPS has a Senior Policy Department whose task is, among others, to provide non-medical, multidirectional care for patients with dementia.

There are no services available in our country that are specific to people with dementia on a wider scale. Care for patients with dementia is provided mainly at home, rarely with institutional support in the patient's place of residence or in day-care centers. A small percentage of patients remain in 24-hour institutional care. There are also Alzheimer's associations and support groups (usually at specialist counselling centers).

Despite the enormous burden of care, much greater than in other chronic diseases, in our country, less frequently than in other developed countries, the family decide on institutional care. In Poland, $92 \%$ of dementia patients stay at home from the onset of the disease until death [41]. According to the results of research conducted by Karczewska et al., over $75 \%$ of caregivers declare that they would not decide on institutional care of their patients under any circumstances [23]. Family carers rarely receive adequate support from the health care system, and are usually left to their own devices. There is also no legal status of a carer of a person suffering from dementia in our country, and there is no formal support system for family carers. There are also no legal solutions that would enable the carer to reconcile care with work. The carer of a disabled person may be granted a maximum of 14 days' leave per year to provide care for family members, which is definitely insufficient in the case of caring for a person with dementia.

In Poland, dementia is diagnosed by geriatrists, neurologists or psychiatrists, and continuation of therapy is carried out by primary care physicians with periodic specialist check-ups. However, the network of diagnostic institutions is definitely insufficient and the waiting time for medical consultation and diagnostic tests is very long. There is also insufficient assistance for patients in the form of daily care centers, support for family carers in the patient's place of residence and the number of inpatient facilities providing 24-hour care for patients. In practice, this means that the system of commercial services is increasingly developing, both in the form of home care and 24-hour care. However, it is a form of service available to a small group of patients and their carers.

In Poland, there is no integration of health services with social welfare and no specific systemic solutions for the care of demented patients. Activities undertaken at the ministerial level (project of the National Alzheimer's Plan, Resolution No. 238 of the Council of Ministers of 24 December 2013 covering the assumptions of the Long-term Senior Policy in Poland for 2014-2020) [22] in practice do not translate into the quality of care for the demented patient, which is still very poor. Compared to other EU countries, Poland is still not prepared to face and resolve the challenge of dementia and create a country that would be friendly to people with cognitive disorders - where there would be easy access to diagnosis, treatment and various forms of institutional care, support for the family carer, the possibility of participation of patients in daily activities accessible to all without exception, without exclusion, social isolation and marginalization. Such solutions have already been adopted in many EU countries, and in other countries plans and strategies for the care of dementia patients are in the process of public consultation [42]. 


\section{Summary}

Dementia is a very important and widespread medical and care problem in ageing societies. In the light of the problems discussed and the results of the many studies presented, which point out that dementia patient care is an immense burden in terms of the time invested and the economic and psychological challenges, this problem must become an important issue for the currently operating care system and for the future planning of health policy in our country.

\section{References}

1. https://stat.gov.pl/obszary-tematyczne/roczniki-statystyczne/roczniki-statystyczne/rocznik-demograficzny-2018,3,12.html (accessed: 10.04.2019).

2. Szukalski P., Decomposition of changes in life expectancy by age groups, Poland, 1950-2008, "Przegl. Epidemiol." 2010; 64 (3): 425-430.

3. Piotrowicz K., Pac A., Skalska A.B., Chudek J., Klich-Rączka A., Szybalska A., Michel J.P., Grodzicki T., Clustering of geriatric deficits emerges to be an essential feature of ageing - results of a cross-sectional study in Poland, "Aging (Albany NY)" 2016; 8 (10): 27.

4. Klich-Rączka A., Siuda J., Piotrowicz K., Boczarska-Jedynak M., Skalska A., Krzystanek E., Wizner B., Świat M., Skrzypek M., Opala G., Grodzicki T., Zaburzenia funkcji poznawczych u osób w starszym wieku, in: Mossakowska M., Więcek A., Błędowski P. (eds.), Aspekty medyczne, psychologiczne, socjologiczne i ekonomiczne starzenia się ludzi w Polsce, Termedia Wydawnictwa Medyczne, Poznań 2012.

5. Skalska A., Wizner B., Piotrowicz K., Klich-Rączka A., Klimek E., Mossakowska M., Rowiński R., Kozak-Szkopek E., Jóźwiak A., Gąsowski J., Grodzicki T., The prevalence of falls and their relation to visual and hearing impairments among a nation-wide cohort of older Poles, "Exp. Gerontol." 2013; 48 (2): 140-146.

6. Diagnostyka i leczenie otępień. Rekomendacje zespotu ekspertów Polskiego Towarzystwa Alzheimerowskiego, Wydawnictwo Medisfera, Otwock 2012.

7. Garre-Olmo J., Garcia-Ptacek S., Calvó-Perxas L., Turró-Garriga O., López-Pousa S., Eriksdotter M., Diagnosis of dementia in the specialist setting: A comparison between the Swedish Dementia Registry (SveDem) and the Registry of Dementias of Girona (ReDeGi), "J. Alzheimers Dis." 2016; 53 (4): 1341-1345.

8. Mayeux R., Stern Y., Epidemiology of Alzheimer Disease, “Cold Spring Harb. Perspect. Med.” 2012; 2 (8): a006239.

9. Ferri C.P., Prince M., Brayne C., Brodaty H., Fratiglioni L., Ganguli M., Hall K., Hasegawa K., Hendrie H., Huang Y., Jorm A., Mathers C., Menezes P.R., Rimmer E., Scazufca M., Alzheimer's Disease International: Global prevalence of dementia: A Delphi consensus study, "Lancet" 2005; 366 (9503): 2112-2117.

10. Klich-Rączka A., Piotrowicz K., Mossakowska M., Skalska A., Wizner B., Broczek K., Wieczorowska-Tobis K., Grodzicki T., The assessment of cognitive impairment suspected of dementia in Polish elderly people: Results of the population-based PolSenior Study, "Exp. Gerontol." 2014; 57: 233-242.
11. Langa K.M., Levine D.A., The diagnosis and management of mild cognitive impairment: a clinical review, "JAMA" 2014; 312 (23): 2551-2561.

12. Petersen R.C., Lopez O., Armstrong M.J., Getchius T.S.D., Ganguli M., Gloss D., Gronseth G.S., Marson D., Pringsheim T., Day G.S., Sager M., Stevens J., Rae-Grant A., Practice guideline update summary: Mild cognitive impairment: Report of the Guideline Development, Dissemination, and Implementation Subcommittee of the American Academy of Neurology, "Neurology" 2018, 16; 90 (3): 126-135.

13. Parnowski T., Szczudlik A., Sobów T., Gabryelewicz T., Zaburzenia neuropsychiatryczne $w$ otepieniach. Uaktualnione zasady terapii, Mediadore, Warszawa 2018.

14. Norton S., Matthews F.E., Barnes D.E., Yaffe K., Brayne C., Potential for primary prevention of Alzheimer's disease: An analysis of population-based data, "Lancet Neurol." 2014; 13 (8): 788-794.

15. Volkert D., Chourdakis M., Faxen-Irving G., Frühwald T., Landi F., Suominen M.H., Vandewoude M., Wirth R., Schneider S.M., ESPEN guidelines on nutrition in dementia, "Clin. Nutr." 2015; 34 (6): 1052-1073.

16. Park-Wyllie L.Y., Mamdani M.M., Li P., Gill S.S., Laupacis A., Juurlink D.N., Cholinesterase inhibitors and hospitalization for bradycardia: A population-based study, "PLoS Med." 2009; 6 (9).

17. Pariente A., Sanctussy D.J., Miremont-Salamé G., Moore N., Haramburu F., Fourrier-Réglat A., L'Association Française des Centres Régionaux de Pharmacovigilance $(C R P V)$ : Factors associated with serious adverse reactions to cholinesterase inhibitors: a study of spontaneous reporting, "CNS Drugs" 2010; 24 (1): 55-63.

18. Little M.O., Updates in nutrition and polypharmacy, "Curr. Opin. Clin. Nutr. Metab. Care" 2018; 21 (1): 4-9.

19. Soler A., Amer G., Leiva A., Ripoll J., Llorente M.A., Leiva A., Taltavull J.M., Molina R., Llobera J., Continuation versus discontinuation of treatment for severe dementia: Randomized, pragmatic, open-label, clinical trial to evaluate the efficacy of continuing drug treatment in patients with severe dementia (STOP-DEM), "BMC Geriatr." 2019; 19 (1): 101.

20. Kuo Y.C., Rajesh R., Challenges in the treatment of Alzheimer's disease: Recent progress and treatment strategies of pharmaceuticals targeting notable pathological factors, "Expert Rev. Neurother." 2019 May 20. doi: 10.1080/14737175.2019.1621750. [Epub ahead of print].

21. Amjad H., David L., Roth D.L., Samus Q.M., Yasar S., Wolff J.L., Potentially unsafe activities and living conditions in older adults with dementia, "J. Am. Geriatr. Soc." 2016; 64 (6): 1223-1232.

22. Sytuacja osób chorych na chorobę Alzheimera w Polsce. Raport RPO, Biuro Rzecznika Praw Obywatelskich, Warszawa 2016; https://www.rpo.gov.pl/sites/default/files/Sytuacja\%20osób\%20chorych\%20na\%20chorobę\%20Alzheimera\%20wyd.II_.pdf (accessed: 02.04.2019).

23. Karczewska B., Bień B., Ołdak E., Jamiołkowski J., Opiekunowie rodzinni osób starszych z otępieniem lub zaburzeniami poznawczymi w Polsce - czynniki ryzyka obciażenia opieka, "Gerontologia Polska" 2012; 20: 2.

24. Black C.M., Ritchie C.W., Khandker R.K., Wood R., Jones E., Hu X., Ambegaonkar B.M., Non-professional caregiver 
burden is associated with the severity of patient' cognitive impairment, "PLoS One" 2018; 13 (12).

25. Klich-Rączka A., Głaś M., Grodzicki T., Stan funkcji poznawczych a zaniedbanie $i$ samozaniedbanie, in: Tobiasz-Adamczyk B., Brzyska M., Grodzicki T. (eds.), Zaniedbanie $i$ samozaniedbanie osób starszych. Medyczne i spoleczne uwarunkowania, Ed. I, Wydawnictwo Uniwersytetu Jagiellońskiego, Kraków 2019: 105-119.

26. Sutcliffe C., Giebel C., Bleijlevens M., Lethin C., Stolt M., Saks K., Soto M.E., Meyer G., Zabalegui A., Chester H., Challis D., on behalf of the RightTimePlaceCare Consortium, Caring for a person with dementia on the margins of longterm care: A perspective on Burden from 8 European countries, “J. Am. Med. Dir. Assoc.” 2017; 18 (11): 967-973.

27. Luengo-Fernandez R., Leal J., Gray A.M., UK research expenditure on dementia, heart disease, stroke and cancer: Are levels of spending related to disease burden? "Eur. J. Neurol." 2012; 19 (1): 149-154.

28. Cantarero-Prieto D., Leon P.L., Blazquez-Fernandez C., Juan P.S., Cobo C.S., The economic cost of dementia: A systematic review, "Dementia (London)" 2019; Mar 25: 1471301219837776 [Epub ahead of print].

29. Deb A., Thornton J.D., Sambamoorthi U., Innes K., Direct and indirect cost of managing alzheimer's disease and related dementias in the United States, "Expert. Rev. Pharmacoecon Outcomes Res." 2017; 17 (2): 189-202.

30. Wimo A., Reed C.C., Dodel R., Belger M., Jones R.W., Happich M., Argimon J.M., Bruno G., Novick D., Vellas B., Haro J.M., The GERAS Study: A prospective observational study of costs and resource use in community dwellers with Alzheimer's disease in three European countries - study design and baseline findings, "J. Alzheimers Dis." 2013; 36 (2): 385-399.

31. Lenox-Smith A., Reed C., Lebrec J., Belger M.W., Resource utilisation, costs and clinical outcomes in non-institutionalised patients with Alzheimer's disease: 18-month UK results from the GERAS observational study, "BMC Geriatr." 2016; 16 (1): 195.

32. Olazarán J., Agüera-Ortiz L., Argimón J.M., Reed C., Ciudad A., Andrade P., Dilla T., Costs and quality of life in community-dwelling patients with Alzheimer's disease in Spain: Results from the GERAS II observational study, “Int. Psychogeriatr.” 2017; 29 (12): 2081-2093.

33. Bruno G., Mancini M., Bruti G., Dell'Agnello G., Reed C., Costs and resource use associated with Alzheimer's disease in Italy: Results from an observational study, "J. Prev. Alzheimers Dis." 2018; 5 (1): 55-64.
34. Belger M., Haro J.M., Reed C., Happich M., Argimon J.M., Bruno G., Dodel R., Jones R.W., Vellas B., Wimo A., Determinants of time to institutionalisation and related healthcare and societal costs in a community-based cohort of patients with Alzheimer's disease dementia, "Eur. J. Health Econ." 2019; 20 (3): 343-355.

35. Tucker S., Sutcliffe C., Bowns I., Challis D., Saks K., Verbeek H., Cabrera E., Karlsson S., Leino-Kilpi H., Meyer G., Soto M.E., RightTimePlaceCare Consortium: Improving the mix of institutional and community care for older people with dementia: An application of the balance of care approach in eight European countries, "Aging Ment. Health" 2016; 20 (12): 1327-1338.

36. Wübker A., Zwakhalen S.M., Challis D., Suhonen R., Karlsson S., Zabalegui A., Soto M., Saks K., Sauerland D., Costs of care for people with dementia just before and after nursing home placement: primary data from eight European countries, "Eur. J. Health Econ.” 2015; 16 (7): 689-707.

37. Schaller S., Mauskopf J., Kriza C.., Wahlster P, Kolominsky-Rabas P.L., The main cost drivers in dementia: a systematic review, "Int. J. Geriatr. Psychiatry" 2015; 30 (2): 111-129.

38. Livingston G., Barber J., Marston L., Stringer A., Panca M., Hunter R., Cooper C., Laybourne A., La Frenais F., Reeves S., Manela M., Lambe K., Banerjee S., Rapaport P., Clinical and cost-effectiveness of the Managing Agitation and Raising Quality of Life (MARQUE) intervention for agitation in people with dementia in care homes: A singleblind, cluster-randomised controlled trial, "Lancet Psychiatry" 2019; 6 (4): 293-304.

39. Panca M., Livingston G., Barber J., Cooper C., La Frenais F., Marston L., Cousins S., Hunter R.M., Healthcare resource utilisation and costs of agitation in people with dementia living in care homes in England - The Managing Agitation and Raising QUality of LifE in Dementia (MARQUE) study, "PLoS One" 2019; 14 (2): e0211953.

40. Costa N., Wübker A., De Mauléon A., Zwakhalen S.M.G., Challis D., Leino-Kilpi H., Hallberg I.R., Stephan A., Zabalegui A., Saks K., Molinier L., Wimo A., Vellas B., Sauerland D., Binot I., Soto M.E., RightTimePlaceCare consortium costs of care of agitation associated with dementia in 8 European countries: Results from the RightTimePlaceCare Study, “J. Am. Med. Dir. Assoc.” 2018;19 (1): 95.e1-95.e10.

41. Durda M., Organizacja opieki nad ludźmi z demencja, "Gerontologia Polska"; 18 (2): 76-85.

42. http://www.alzheimer-europe.org/Policy-in-Practice2/National-Dementia-Plans (accessed: 12.04.2019). 